Original Article

\title{
EVALUATION OF POMEGRANATE PEEL AS A SUBSTRATE FOR CITRIC ACID PRODUCTION BY ASPERGILLUS NIGER
}

\author{
PAYEL SUTRADHAR ${ }^{*}$, ISHIKA SAHA ${ }^{2}$, AMIT CHAKRAVARTY ${ }^{3}$
}

${ }^{1 *}, 2$ Department of Microbiology, ${ }^{3}$ Department of Biotechnology, Institute Of Genetic Engineering. Kolkata- 700128, West Bengal, India. Email: payel.sutradhar@gmail.com

Received: 20 Jan 2020, Revised and Accepted: 19 Mar 2020

\section{ABSTRACT}

Objective: The present study aimed to evaluate dried pomegranate peels as a substrate for citric acid production by Aspergillus niger.

Methods: The morphological study of Aspergillus niger was carried out by wet mount with lactophenol cotton blue and slide culture method. A preliminary qualitative screening of citric acid-producing ability of this fungal strain was also performed by using the Czapek-Dox agar medium containing Bromocresol green. Dried and finely powdered Pomegranate peel was used as a principal substrate for the production of citric acid by submerged fermentation. Classical method of citric acid recovery involved a precipitation technique using calcium hydroxide followed by filtration and subsequent treatment with sulphuric acid. The citric acid produced was also chemically detected and titrimetrically estimated by $0.1 \mathrm{~N}$ NaOH.

Results: The present experiment demonstrated that pomegranate peels may serve as an inexpensive medium for the production of citric acid with a yield of $19.39 \mathrm{~g} / \mathrm{l}$ by using Aspergillus niger.

Conclusion: This study provided an alternative basis to recycle the fruit peel waste of pomegranate in order to achieve industrially feasible and environmentally sustainable bio-production of pharmaceutically significant citric acid.

Keywords: Aspergillus niger, Citric acid, Pomegranate peel, Czapek-Dox agar, Bromocresol green, Fermentation, GRAS

(C) 2020 The Authors. Published by Innovare Academic Sciences Pvt Ltd. This is an open access article under the CC BY license (http://creativecommons.org/licenses/by/4.0/) DOI: http://dx.doi.org/10.22159/ijcpr.2020v12i3.38307. Journal homepage: https://innovareacademics.in/journals/index.php/ijcpr

\section{INTRODUCTION}

Citric acid is considered as one of the important organic acids that have a wide commercialization potential. The production of citric acid has elevated rapidly, reaching about 1.7 million tons per annum with $5 \%$ predicted annual increase in the rate of production in order to meet the growing needs of the global market [1]. Currie in 1917 performed pioneering work on citric acid production. He worked upon Aspergillus niger for citric acid production using sucrose as a substrate [2]. Citric acid is used in the food and beverage industry to flavour fruit juices, candy ice cream etc. In the pharmaceutical industry, citric acid is used as an acidulant in mild astringent formulations, in rapid dissolution of active ingredients, as an anticoagulant, effervescent in powders and tablets in combination with bicarbonates, solubilization action for cathartics, antioxidant in vitamin preparations, metallic-ion chelator and buffering agent, as an antioxidant and cosmetic preparation. In the chemical industry, it is used as an antifoam agent and for the treatment of textiles $[3,4]$. Recently, major production of citric acid was conducted via microbial fermentation, as it was economical and easy to handle. It is a product adjudged to be GRAS (Generally Recognized as Safe). The food industry consumes about $70 \%$ of total citric acid produced and pharmaceutical industries consume about $12 \%$ and the remaining $18 \%$ are consumed by other industries. The demand for citric acid is increasing faster than its production and hence, more economical processes are required [4].

The two most important microbial sources are bacteria and fungi. But fungus remains the preferred sources for citric acid production.
Aspergillus niger was the most commonly used fungus for citric acid production due to the high yield and relatively high tolerance to acid accumulation without secretion of toxic metabolites, ease of handling and ability to ferment a variety of cheap raw materials [5]. Commercial production of citric acid is generally by submerged fermentation of sucrose or molasses using the filamentous fungus Aspergillus niger or synthetically from acetone or glycerol. It has been reported that fruit peels of mango, banana and orange have been used for citric acid production by using Aspergillus niger [6]. The pomegranate peels contains carbohydrate approximately of $59.98 \pm 1.52 \mathrm{~g} / 100 \mathrm{~g}$ dry peel [7]. Carbon, nitrogen, phosphorus sources, $\mathrm{pH}$ of culture medium, the concentration of alcohols, trace elements like manganese, zinc, copper, magnesium, iron and aeration are some of the factors which influence citric acid fermentation [8].

The current work demonstrated the use of pomegranate fruit peels for the production of citric acid by Aspergillus niger. This study also highlighted the alternative strategy for waste management of fruit waste and extracting best out of waste.

\section{MATERIALS AND METHODS}

\section{Collection and pre-treatment of substrates}

The pomegranate peels were procured from the local registered fruit juice shop of DumDum area of Kolkata, West Bengal (India). The collected peels were cleaned and sundried initially for $2 \mathrm{~d}$ and followed by drying at $50{ }^{\circ} \mathrm{C}$ for 2 hours. Fresh fruit peels were cut into small pieces and ground to a powder (fig. 1).

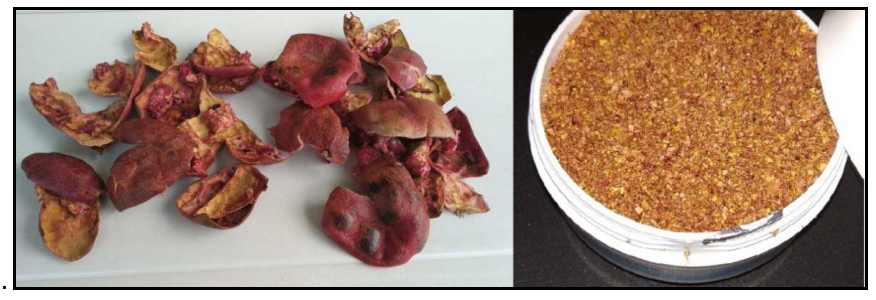

Fig. 1: Dried pomegranate peels and ground to powder 


\section{Isolation and preparation of inoculums}

Aspergillus niger provided by the Microbiology department of the Institute of Genetic Engineering was subcultured on PDA (potato dextrose agar) medium. After 3 days of incubation at $25-30{ }^{\circ} \mathrm{C}$, the well-grown fungal specimen was morphologically studied by wet mount (Lactophenol cotton blue) [9] and slide culture method under the microscope [10].

\section{Qualitative screening for citric acid production}

The fungus was qualitatively studied for the citric acid production using acid indicator medium containing Bromocresol green [11] at $\mathrm{pH}$ 6. The screening medium Czapek-Dox agar was prepared which contained (g/l): $\mathrm{NaNO}_{3}$ (Sodium nitrate) 2.0 as nitrogen source, $\mathrm{K}_{2} \mathrm{HPO}_{4}$ (Dipotassium hydrogen phosphate) 1.0, $\mathrm{MgSO}_{4} .7 \mathrm{H}_{2} \mathrm{O}$ (Magnesium sulphate) 0.5, KCl (Potassium chloride) 0.5, $\mathrm{FeSO}_{4}$ (Ferrous sulphate) 0.01, sucrose 20 for carbon source, Agar 20, Bromocresol green dye $40.0 \mathrm{ml}(1.0 \%, \mathrm{w} / \mathrm{v})$, in distilled water. The screening medium was autoclaved at $15 \mathrm{lbs}$ for $15 \mathrm{~min}$ and inoculation was made in the centre of Petri plate containing the solidified medium. The plate was incubated for $5 \mathrm{~d}$ at $25-30^{\circ} \mathrm{C}$ under static conditions.

\section{Preparation and inoculation of fermentation media}

Submerged fermentation was carried out for the bioproduction of citric acid. A basal medium was prepared by introducing $25 \%$ pomegranate peel powder into a separate $500 \mathrm{ml}$ Erlenmeyer flask. This basal medium was also supplemented with distilled water, 0.25 $\mathrm{g} / \mathrm{l}$ ammonium sulphate $\left(\mathrm{NH}_{4}\right)_{2} \mathrm{SO}_{4}, 0.5 \mathrm{~g} / \mathrm{l}$ potassium dihydrogen phosphate $\mathrm{KH}_{2} \mathrm{PO}_{4}, 0.01 \mathrm{~g} / \mathrm{lCuSO}_{4}, 0.001 \mathrm{~g} / \mathrm{lFeSO}_{4}$. The $\mathrm{pH}$ was checked to 2-3. The flask was cotton plugged and autoclaved at $15 \mathrm{lbs}$ for 15 min. After cooling at room temperature, each medium was aseptically inoculated with a sporulating culture of Aspergillus niger and incubated in a shaker incubator at $30^{\circ} \mathrm{C}$ for $8 \mathrm{~d}$ [12].

\section{Recovery by precipitation using $\mathrm{Ca}(\mathrm{OH})_{2}$}

After $8 \mathrm{~d}$ of incubation, the fermentation medium was separated from the fungal myecelium by filtration using Whatman's filter paper No.1 [13]. Calcium hydroxide was added to the filtrate, warmed and stirred for 1 hour. The precipitate was recovered by centrifugation at $3000 \mathrm{rpm}$ for $10 \mathrm{~min}$ and dried at room temperature. Conc. $\mathrm{H}_{2} \mathrm{SO}_{4}$ was added to the above precipitate and stirred for $1 \mathrm{hr}$. The detection of citric acid was qualitatively confirmed by a few chemical tests.

\section{Qualitative tests for citric acid}

\section{Cadmium chloride test}

Three $\mathrm{ml}$ of test filtrate was mixed with a few drops of dilute $\mathrm{NH}_{4} \mathrm{OH}$ and excess cadmium chloride solution [14].

\section{Calcium chloride test}

To a small quantity of the test filtrate, a few drops of $5 \% \mathrm{CaCl}_{2}$ solution was added.

\section{Calcium carbonate test}

A few drops of a calcium carbonate solution was allowed to react with the test filtrate in a watch glass.

\section{Citric acid estimation by titration}

The filtered broth was centrifuged at 5000rpm for $10 \mathrm{~min}$ and the supernatant was isolated for citric acid estimation. Citric acid was estimated titrimetrically by using standardized $0.1 \mathrm{~N} \mathrm{NaOH}$ and phenolphthalein as an indicator and calculated according to the formula [15].

$$
\mathrm{N}_{1} \mathrm{~V}_{1}=\mathrm{N}_{2} \mathrm{~V}_{2}
$$

Where, $\mathrm{N}_{1}=$ Normality of $0.1 \mathrm{NNaOH}, \mathrm{V}_{1}=$ Volume of $\mathrm{NaOH}, \mathrm{N}_{2}=$ Normality of citric acid, $\mathrm{V}_{2}=$ Volume of citric acid present in the sample.

\section{RESULTS AND DISCUSSION}

Citric acid consumption is gradually increasing due to more advanced applications coming to light. Different techniques for the hyperproduction of citric acid are continuously being studied from the past few decades. Still, there is a gap, and hence, there is an obvious need to consider new strategies to achieve environmentally sustainable bio-production of citric acid.

\section{Study of fungal culture}

The mycelial growth of Aspergillus niger was studied after growing in PDA media, by mounting with lactophenol cotton blue stain, which effectively stains the chitin of the fungal cell wall. The microscopic view identified the large conidial heads with a globose structure, radiate and biseriate with metulae (fig. 2a). The slide culture method also demonstrated the characteristic hyphal growth of A. niger (fig. 2b).

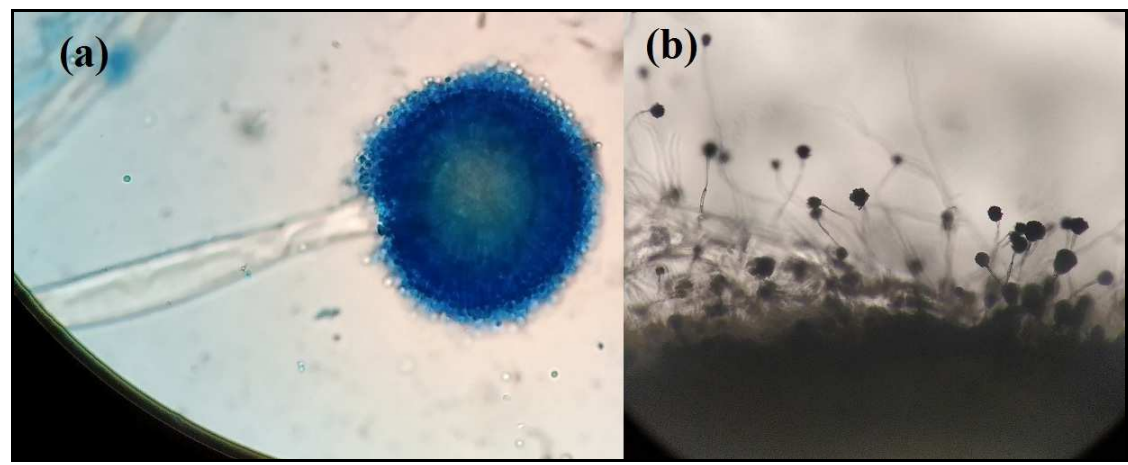

Fig. 2: Microscopic view (40X) of (a) A. niger stained with Lactophenol cotton blue; (b) Slide culture

\section{Preliminary qualitative screening for citric acid production}

The experiment was conducted to choose citric acid-producing fungal strain using plates of Czapek-Dox agar containing Bromocresol green as an indicator and yellow zones around the mycelial growth indicated citric acid production. The diameter of the yellow zone was recorded as $15 \mathrm{~mm}$ (fig. 3).

\section{Fermentation process}

Inoculation of the fermentation broth supplemented with pomegranate peel with the sporulating culture of Aspergillus niger was done aseptically and incubated on a shaker incubator at $30^{\circ} \mathrm{C}$ for 8days. After the incubation period, a dense mycelial growth was observed (fig. 4a-e). This submerged fermentation method demonstrated an environmentally friendly and economical way for valuable organic acid production. Simple filtration, chemical tests and recovery methods were further followed and satisfactory results were obtained.

\section{Recovery of citric acid}

Filtration by Whatman's filter paper No.1 separate fungal mycelia from the fermentation medium. On addition of Calcium hydroxide to the 
filtrate, a fine white precipitate of calcium citrate was formed. The precipitate was reacted with Conc. $\mathrm{H}_{2} \mathrm{SO}_{4}$ and stirred for $1 \mathrm{hr}$, which resulted in the precipitation of calcium sulphate (gypsum), leaving calcium citrate in the aqueous phase (fig. 5). Finally, the gypsum was separated by filtration and test filtrate was further analyzed for the presence of citric acid qualitatively by a few chemical tests.

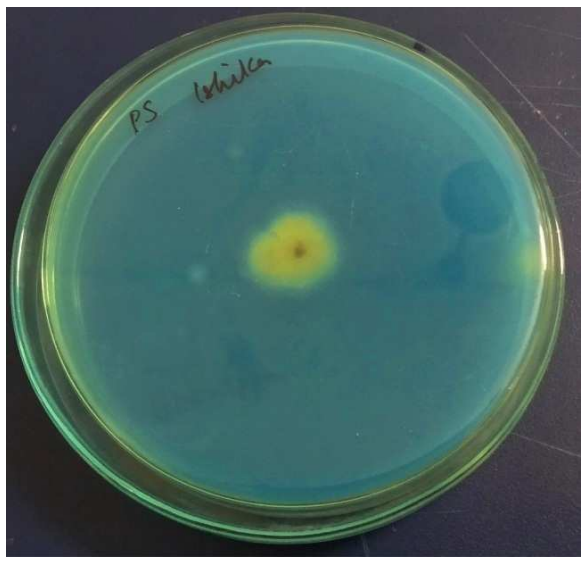

Fig. 3: Czapek-dox agar with bromocresol green (citric acid-producing strain $A$. niger showing yellow zone)

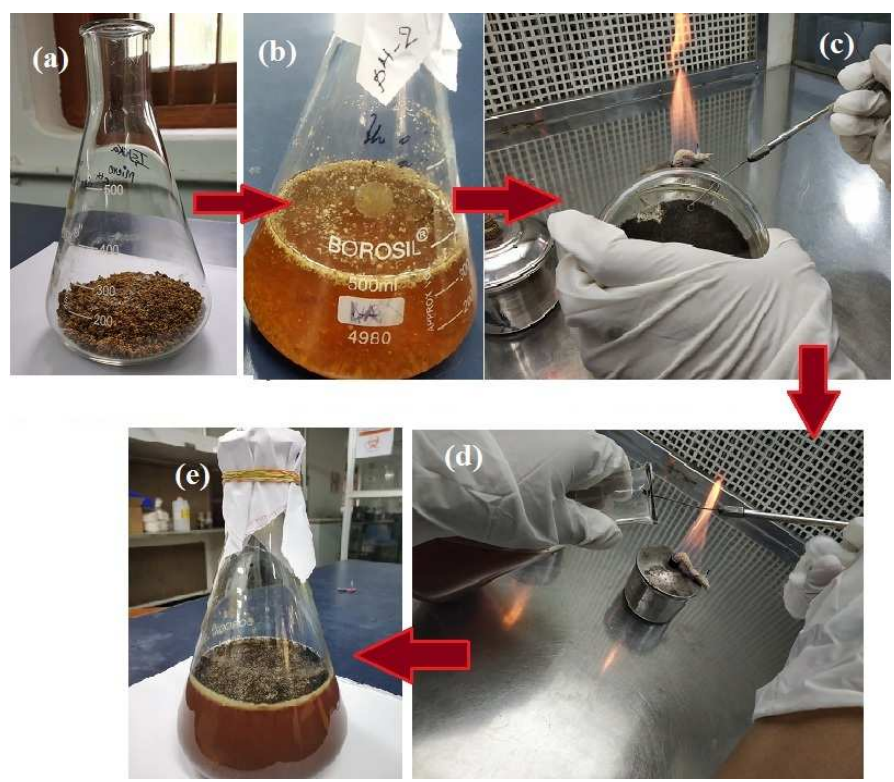

Fig. 4: (a,b)-Pomegranate peel supplemented basal fermentation media; (c,d)-inoculation of fermentation broth media; (e) Mycelial Growth of $A$. niger in fermentation media

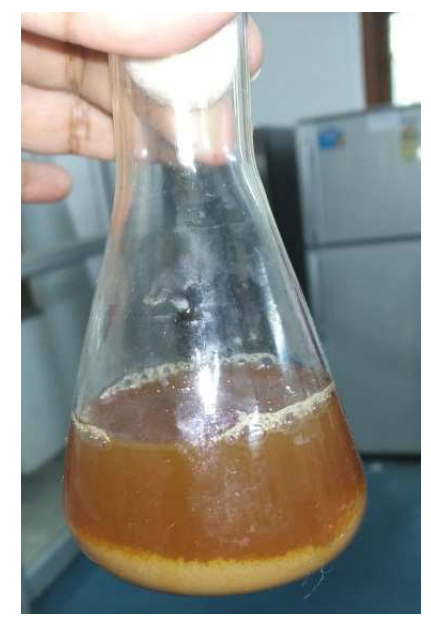

Fig. 5: Precipitation of calcium sulphate leaving calcium citrate in the solution 


\section{Qualitative tests for citric acid}

The chemical tests of the test filtrate recovered from the fermentation medium, with $\mathrm{CdCl}_{2}, \mathrm{CaCl}_{2}$ and $\mathrm{CaCO}_{3}$ confirmed the presence of citric acid.

\section{Cadmium chloride test}

When the test filtrate was mixed with a few drops of dilute $\mathrm{NH}_{4} \mathrm{OH}$ and excess cadmium chloride solutions, a gelatinous white precipitate of cadmium citrate was formed after boiling for $15 \mathrm{~min}$ in a water bath which indicated a positive test for the presence of citric acid (fig. 6a).

\section{Calcium chloride test}

To a small quantity of the test filtrate, a few drops of $5 \% \mathrm{CaCl}_{2}$ solution was added. Immediate precipitation was not observed, whereas on boiling in a water bath, the formation of a white precipitate of calcium citrate indicated the presence of citric acid (fig. 6b).

\section{Calcium carbonate test}

When Calcium carbonate solution was allowed to react with the test filtrate, strong effervescence was liberated, which indicated the release of carbon dioxide gas. When the effervescence ceased, a leftover trace white precipitation of calcium citrate in the watch glass proved the presence of citric acid in the filtrate sample (fig. 6c).

\section{Quantitative estimation of citric acid by titration}

The titration of the test filtrate with $0.1 \mathrm{~N} \mathrm{NaOH}$ in the presence of phenolphthalein as the indicator was experimentally conducted. This titrimetric analysis also showed that pomegranate peel can be an inexpensive medium for the production of citric acid with a satisfactory yield of $19.39 \mathrm{~g} / \mathrm{l}$ citric acid (fig. $7 \mathrm{a}, \mathrm{b}$ ).

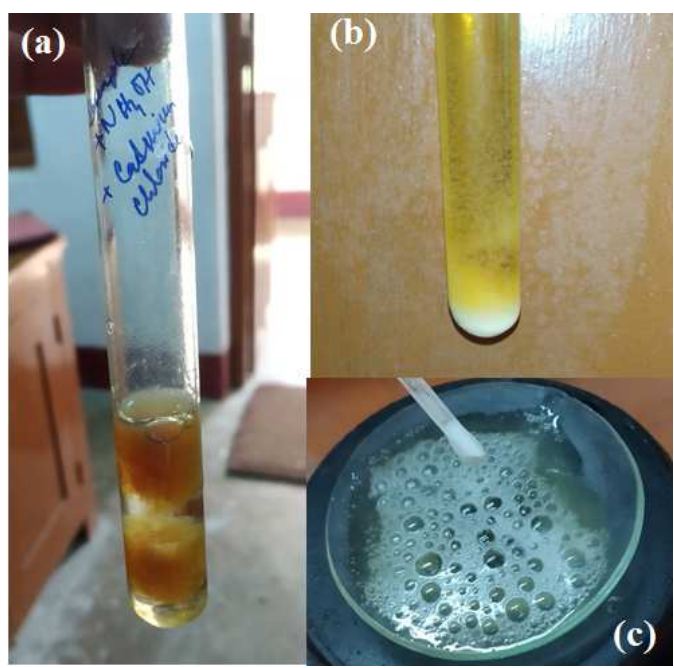

Fig. 6: (a) gelatinous precipitate in cadmium chloride test (b) White precipitate calcium chloride test (c)Effervescence of $\mathrm{CO}_{2}$ in calcium carbonate test

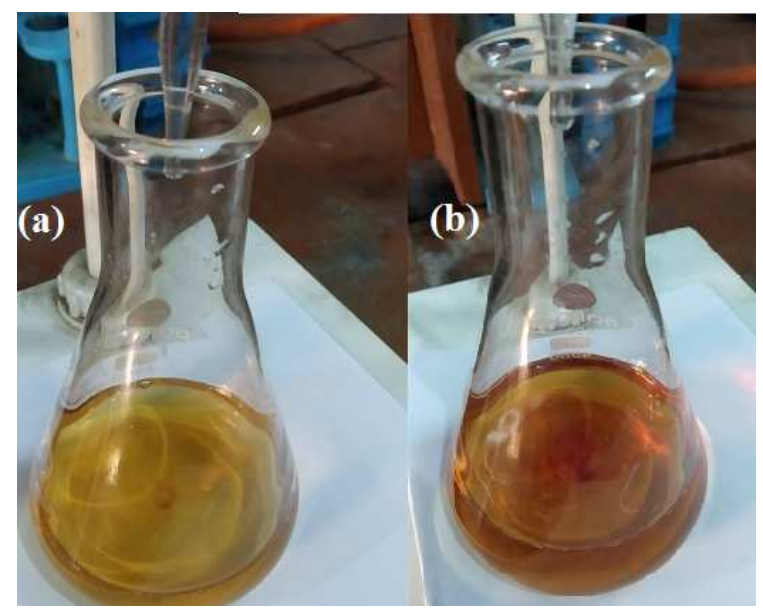

Fig. 7: (a) Titration of the filtered broth with $0.1 \mathrm{~N} \mathrm{NaOH}$; (b) Colour change of the sample indicating the endpoint

In the present investigation, proper utilization of fruit peel waste as a substrate for Aspergillus niger for the production of citric acid was proved successfully with simple economical and cost-effective methods. The present work successfully fulfilled the insight for better utilization of fruit waste for citric acid production, which may offer an advantageous strategy towards waste management and pollution in the environment. The conducted work also serve for a few significant by-products after the fermentation process like gypsum, which has also a great role in many field of industries.

\section{CONCLUSION}

This study has evaluated pomegranate peels as a potential substrate for the production of citric acid and its utilization will facilitate large-scale production of this commercially valuable organic acids. The present study emphasizes on the choices of sources for the citric-acid producing microorganisms and the waste raw materials. Moreover, the waste pomegranate peels successfully served as a carbohydrate source for citric acid production by Aspergillus niger. 
Hence, the fruit peel waste could be reused for the production of industrially and pharmacologically important organic acids like citric acid. The present investigation may conclude that, in spite of throwing the peels away, we can recycle the pomegranate fruit peels in a cost-effective way to produce industrially important substances.

\section{ACKNOWLEDGMENT}

The authors acknowledge the Director and Vice-Principal of Institute of Genetic Engineering (IGE) for funding and affiliation. We are also thankful to other laboratory members of IGE for their enthusiastic participation in the present work.

\section{FUNDING}

Nil

\section{AUTHORS CONTRIBUTIONS}

All the authors have contributed equally.

\section{COMPETING INTERESTS}

The authors report no conflicts of interest in this work

\section{REFERENCES}

1. Ali Hayder KQ. Economic benefit from the optimization of citric acid production from rice straw through Plackett-Burman design and central composite design. Turkish J Eng Environ Sci 2012;36:81-93.

2. Pandey P, Putatunda S, Dewangan L, Pawar VS, Belorkar SA. Studies on citric acid production by Aspergillus niger in batch fermentation. Recent Res Sci Technol 2013;5:66-7.

3. Kuforiji O, Kuboye AO, Odunfa SA. Orange and pineapple wastes as potential substrates for citric acid production. Int J Plant Biol 2010;1:19-21.

4. Sawant O, Mahale S, Ramchandran V, Nagaraj G, Bankar A. Fungal citric acid production using waste materials: a minireview. J Microbiol Biotechnol Food Sci 2018;8:821-8.
5. Pandey A, Soccol CR, Rodriguez Leon JA, Nigam P. Production of organic acids by solid-state fermentation. In: Solid-state fermentation in biotechnology-fundamentals and applications. Asiatech Publishers Inc New Delhi India 2001;4:113-26.

6. Abbas N, Safdar W, Ali S, Choudhry S, Elahi S. Citric acid production from Aspergillus niger using mango (Mangifera indica $\mathrm{L}$.) and sweet orange (Citrus sinensis) peels as substrate. Int J Sci Eng Res 2016;7:868-72.

7. Romelle FD, Ashwini Rani P, Manohar RS. Chemical composition of some selected fruit peels. Eur J Food Sci Technol 2016;4:12-21.

8. Show PL, Oladele KO, Qi Yan Siew. Overview of citric acid production from Aspergillus niger. Frontiers Life Sci 2015;8:271-83.

9. Cappuccino and sherman, fungal identification, a laboratory manual, USA, Pearson education. 10th ed. 2014. p. 237-42.

10. Wijedasa MH, Liyanapathirana LVC. Evaluation of an alternative slide culture technique for the morphological identification of fungal species. Sri Lanka J Infectious Diseases 2012;2:47-52.

11. Vidya P, Annapoorani AM, Jalalugeen H. Optimization and utilisation of various fruit peel as substrate for citric acid production by Aspergillus niger isolated from orange and carrot. Pharma Innovation J 2018;7:141-6.

12. Kareem SO, Rahman RA. Utilization of banana peels for citric acid production by Aspergillus niger. Agric Biol J North Am 2011;4:384-7.

13. Kareem SO. Production of citric acid by Aspergillus niger using pineapple waste. Malaysian J Microbiol 2010;6:161-5.

14. Chetan, Sarang SF. Comparison of citric acid production from Aspergillus niger in solid and suspension state fermentation. International Journal of Green Pharmacy 2018;Suppl 12:S502S509.

15. Iralapati V, Kummari S. Production of citric acid from different fruit peels using Aspergillus niger. Int J Sci Eng Res 2015;3:12930 . 